\title{
Observatorio
}

\section{Comunicación en la empresa y apertura del perfil profesional de los documentalistas}

\author{
Por Javier Leiva-Aguilera
}

\begin{abstract}
Resumen: Las plataformas de la web social han sido el desencadenante de la aparición de un nuevo perfil de profesional llamado community manager. Se analiza la posibilidad de que los graduados en información y documentación puedan acceder a ese puesto teniendo en cuenta las competencias demandadas en las ofertas de trabajo actuales, así como la presencia de dichas competencias y de las materias requeridas en la configuración del grado en las universidades españolas.

Palabras clave: Gestor de comunidad, Web 2.0, Web social, Imagen corporativa, Relación con los usuarios, Relación con los clientes, Perfil profesional, Empleo, Mercado de trabajo, Habilidades, Curriculum, Plan de estudios, Profesional de la información, Bibliotecario, Documentalista.

Title: Corporate communication and the expansion of the librarians professional profile

Abstract: The explosion of social web platforms has triggered the emergence of a new professional profile called community manager. The opportunities for graduates in library sciences to have access to these jobs are analyzed, taking into account the skills demanded in the current job offers and how Spanish universities have integrated them in their curricula.
\end{abstract}

Keywords: Community manager, Web 2.0, Social web, Corporate image, Users relationship, Customer relations, Professional pro-

file, Employment, Labour market, Skills, Curriculum, Information professional, Information scientist, Librarian.

Leiva-Aguilera, Javier. "Comunicación en la empresa y apertura del perfil profesional de los documentalistas”. El profesional de la información, 2010, marzo-abril, v. 19, n. 2, pp. 117-121.

DOI: 103145/epi.2010.mar.01

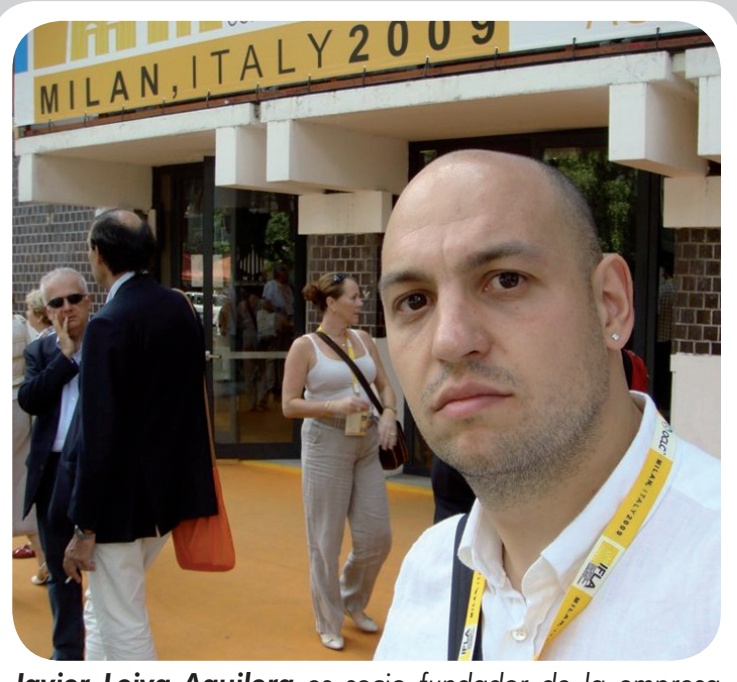

Javier Leiva-Aguilera es socio fundador de la empresa Catorze Asesoría Internet (Catorze.com), profesor de los estudios de información y documentación de la Universitat de Vic, del máster en comunicación 2.0 de la Universidad de Alcalá y director del programa formativo de gestor y mediador de la información que organizan Tabakalera y la Fundación Asmoz. Es asesor externo de varias empresas en materia de web social y reputación online y conferenciante habitual sobre el tema.

\section{La web social y la comunicación empresarial}

LA COMUNICACIÓN EMPRESARIAL EN INTERNET ya no se reduce, como hace unos años, a la publicidad de pago. Hoy en día las empresas pueden usar este canal directo para vender pero también para fidelizar al cliente, para ofrecerle un servicio post-venta eficaz, para pedirle ayuda en el desarrollo de nuevos productos, etc.

La Red como plataforma comercial efectiva existe desde hace más de quince años, pero desde hace algunos menos se ha producido un cambio radical en el clásico esquema de comunicación emisor-receptor. Actualmente el modelo es mucho más abierto y empresas y consumidores pasan a representar ambos papeles al 
ser consultada instantáneamente por una audiencia mundial. Por su parte, esas empresas tienen ante sí la maravillosa posibilidad de recibir de forma directa información muy valiosa de cara a su mejora continua... siempre que estén a la escucha. En caso contrario, la realidad les puede jugar en contra y ser presa fácil de la pérdida de prestigio (aunque ellos no la vean, la información es pública y otros sí lo harán).

Esta nueva situación obliga a las empresas a entender los nuevos medios y a participar en ellos de forma sincera y transparente. Está claro (y es lógico) que quieren seguir vendiendo, pero para ello deben empezar a olvidar los clásicos folletos o catálogos sensacionalistas (y generalmente sospechosos) o fríos (e incapaces de generar ninguna emoción en el público) y ponerse en un plano de igualdad con las personas. Esto no es posible de forma directa porque la comunicación puede funcionar muy bien entre dos personas, pero nunca lo hace de igual modo entre una persona y una entidad. Así que se hace necesaria la figura de un intermediario: el community manager.

\section{"El desarrollo de la web social obliga a las empresas a buscar un profesional que las acerque a los consumidores con una voz humana"}

\section{Voz, imagen y emoción de la empresa}

Si la forma en la que la empresa comunica debe cambiar, ¿sirven los mismos profesionales que se han estado ocupando hasta ahora de este tema? Parece lógico que los responsables del marketing y la comunicación, que ya se ocupaban de difundir las bondades de las organizaciones, modifiquen sus funciones y complementen su formación para quedarse con esa tarea; su perfil es cercano a lo que se necesita y pueden hacerlo. Pero... ¿podrían hacerlo también los profesionales de la información? Una respuesta sin análisis podría ser negativa porque es habitual (cuando se habla de personas de nuestro perfil dentro de un sector empresarial concreto) pensar en alguien trabajando en una pequeña biblioteca o centro de documentación desarrollando las funciones técnicas clásicas: selección, adquisición, análisis documental, organización, difusión (interna, la mayoría de las veces). Pero lo mejor es que nos acerquemos a la figura del community manager para poder llegar a una conclusión más meditada.

La denominación de community manager se podría traducir como gestor de comunidades online, ya sean éstas específicas (una red social especializada, por ejemplo) o globales (todo el conjunto de plataformas sociales que sean de interés para los objetivos corporativos). Se trata de un perfil que adopta una posición intermedia entre la empresa y los consumidores, por lo que va más allá del puro altavoz empresarial en un nuevo medio (lo que sería equivalente al folleto anteriormente mencionado). En vez de eso, trata de hacer saber a los consumidores qué ofrece la empresa a la que representa y al mismo tiempo intenta defender ante su empresa a dichos consumidores. Podríamos decir que es una especie de mediador digital, alguien que transforma la relación empresa-consumidor-empresa haciendo de intermediario entre las partes.

Las funciones del community manager, según Aer$\mathrm{co}^{2}$, son las siguientes:

1. Escuchar lo que se publica sobre la empresa y su sector: de este modo toma el pulso al mercado y tiene conocimiento de lo que hace la competencia y de lo que los usuarios o clientes piensan sobre su oferta de productos o servicios.

2. Circular internamente la información que recibe para que llegue a los departamentos o personas clave en cada caso.

3. Explicar la posición de la empresa a la comunidad con una voz más cercana que la clásica empresarial.

4. Buscar líderes, tanto interna como externamente.

5. Encontrar vías de colaboración entre la comunidad y la empresa.

\section{"Un community manager debe saber escuchar, responder, informar y conectar a las personas adecuadas (Jeremiah Owyang)"}

Jeremíah Owyang ${ }^{3}$ se pronuncia en el mismo sentido afirmando que un community manager debe saber escuchar, responder, informar y conectar a las personas adecuadas $^{4}$. De entre estas cualidades y funciones podemos extraer tareas muy ligadas a la vigilancia tecnológica y la inteligencia competitiva, ambas totalmente ligadas al perfil del profesional de la información. Otras tienen más relación con la comunicación y la mediación.

Visto así, no parece que el perfil del profesional de la información quede demasiado lejos de la línea de salida para ocupar parte de la demanda de community 


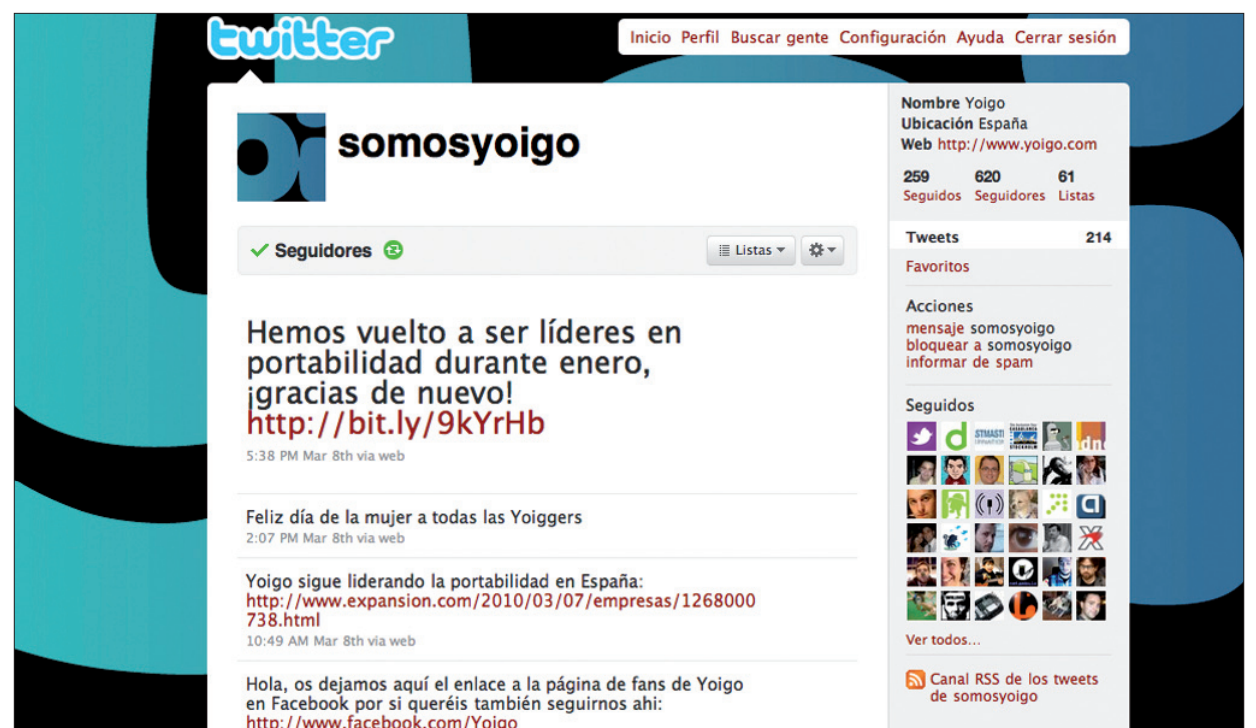

Perfil de Twitter del community manager de la empresa Yoigo http://twitter.com/somosyoigo
- Conocimientos de informática relativos al ámbito de estudio

- Creatividad

- Habilidades en las relaciones interpersonales

- Iniciativa y espíritu emprendedor

- Liderazgo

- Motivación por la calidad

- Resolución de problemas

- Toma de decisiones

- Trabajo en equipo managers, si bien es cierto que las personas que quieran acercarse a ese nicho deberán cubrir las lagunas relacionadas con la comunicación y la mediación.

\section{La formación previa al puesto}

Viendo las ofertas de empleo relacionadas con este tema ${ }^{5}$ comprobamos que las empresas demandantes no contemplan en principio como candidato el perfil del documentalista. De entre la muestra observada, vemos que se solicitan personas con las siguientes titulaciones:

- Comunicación

- Periodismo

- Comunicación y marketing

- Humanidades

- Administración de empresas

- Formación profesional de grado superior (sin especificar ámbito)

No obstante, si nos fijamos en las competencias que se esperan de un community manager y las comparamos con las que aparecen como genéricas en el Libro blanco del título de grado en información y documentación ${ }^{6}$, observamos que aparecen todas. En la siguiente lista podemos ver las que han surgido del análisis de las ofertas observadas:

- Adaptación a nuevas situaciones

- Aprendizaje autónomo

- Capacidad de aprendizaje

- Comunicación oral y escrita

- Conocimiento de una lengua extranjera
Pero cubrir las competencias genéricas demandadas no quiere decir forzosamente que los graduados en información y documentación llegarán al mercado laboral con los conocimientos y sobre todo, las actitudes, necesarios para cubrir estos puestos de trabajo. En la definición del perfil que hace el libro blanco no se tiene en cuenta esa salida profesional:

"El titulado en biblioteconomía y documentación debe estar capacitado para trabajar como gestor de la información/documentación y en el servicio al usuario en cualquier tipo de unidad o servicio de información, y como gestor de contenidos".

Aunque no se deja la puerta cerrada:

"Esto no obsta para que, a partir de las asignaturas obligatorias y optativas que cada universidad determine, los alumnos puedan profundizar en la adquisición de determinadas capacidades que les orienten a salidas profesionales concretas, y que las mismas universidades puedan ofrecer una cierta diversidad de enfoques una vez asegurada una formación básica común".

Por lo tanto habría que confiar en que por lo menos en la configuración de las asignaturas optativas se haya tenido en cuenta la posibilidad de que los estudiantes salgan formados para ocupar puestos de community manager. Para ello deberían cubrirse los siguientes temas presentes en las ofertas de empleo:

- Analítica web

- Industria publicitaria

- Marketing viral

- Posicionamiento en buscadores

- Redacción de textos

- Sistemas de gestión de contenidos 


\section{InfoJobs.net}

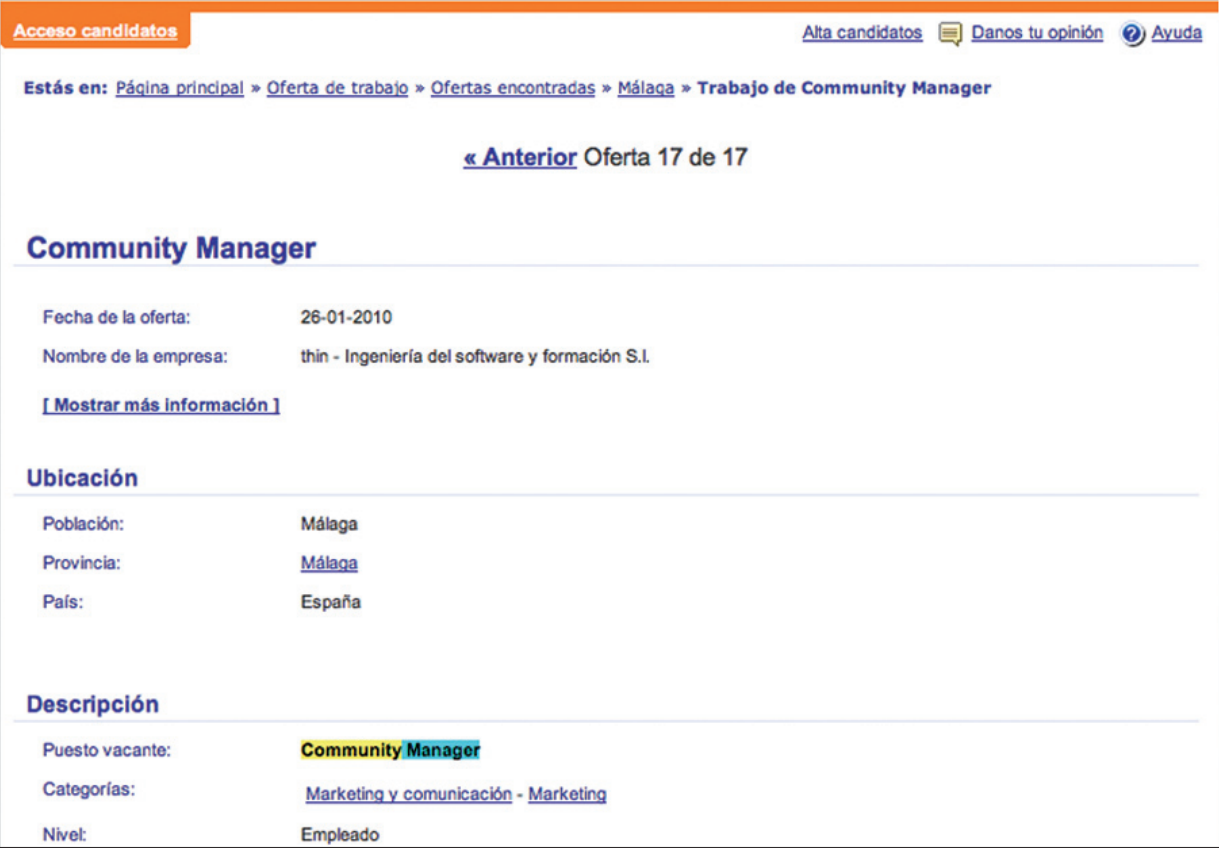

Oferta de empleo buscando un community manager, en Infojobs

apuntados son la de redes sociales y la de gestión avanzada de contenidos. Las demás bien podrían tener una orientación hacia la visión clásica de la biblioteconomía y documentación, ya que todas ellas figuran desde hace tiempo en las antiguas diplomaturas y licenciaturas.

\section{Abrir la mente es optar a más puestos}

La conclusión que sacamos de lo anterior parece desalentadora: se ha abierto una gran ventana de empleo que podría ser cubierta por profesionales formados en las facultades de información y documentación $\mathrm{y}$ por el momento en dicho ámbito no se ha detectado esa oportunidad. Así pues, los re-

- Técnicas comerciales

- Plataformas de la web social

¿Se ha tenido en cuenta esta necesidad del mercado en la definición de los grados en información y documentación programados en las universidades españolas? La respuesta es negativa.

Al consultar los planes de estudio que están ofreciendo el grado en información y documentación durante el curso 2009-10 detectamos sólo unas pocas asignaturas que podrían ser susceptibles de incorporar algunos de esos elementos. Podemos verlas en el cuadro 1.

De todas las anteriores, las únicas que parecen estar directamente relacionadas con los conocimientos cién graduados deberán recibir formación complementaria si quieren orientar su carrera hacia este campo. ¿Es este un caso único? Todo lo contrario: en un mercado tan cambiante como el actual, todos estamos obligados a formarnos y reinventarnos continuamente si queremos seguir resultando competitivos. Como decía Kim Dority en Multiple knowledge bases = multiple job opportunities", "if you stay in the world of librarianship,

\section{"Las empresas que buscan un community manager no se plantean que un documentalista puede ser adecuado para el puesto"}

\begin{tabular}{|l|l|c|}
\hline \multicolumn{1}{|c|}{ Asignatura } & \multicolumn{1}{c|}{ Universidad } & Tipo de asignatura \\
\hline Avances en tecnologías de la información & Universidad de Salamanca & Optativa \\
\hline Gestión avanzada de contenidos & $\begin{array}{l}\text { Universitat Oberta de Catalunya } \\
\text { Universidad de León } \\
\text { Universidad Carlos III de Madrid }\end{array}$ & Optativa \\
\hline Información y formatos digitales & Universitat de Barcelona & Básica \\
\hline Informática especializada & Universidad Complutense de Madrid & Optativa \\
\hline Redes sociales & Universitat Oberta de Catalunya & Básica \\
\hline Técnicas de gestión y comunicación & Universitat Oberta de Catalunya & Optativa \\
\hline Tecnologías de internet & Universidad Carlos III de Madrid & Básica \\
\hline Teoría de la comunicación & $\begin{array}{l}\text { Universidad Complutense de Madrid } \\
\text { Universitat Oberta de Catalunya } \\
\text { Universidad Carlos III de Madrid }\end{array}$ & \\
\hline
\end{tabular}


you'll continue to develop your LIS knowledge base. However, if you want to open up more job options, consider actively looking for ways to develop multiple knowledge bases".

Volviendo a la pregunta del segundo punto, no parece tan extraño que un documentalista pueda acceder a un puesto de community manager. Eso sí: deberá abrir su mente y prepararse para ello sabiendo que va a competir con profesionales de otras ramas.

\section{Notas}

1. Levine, Rick; Locke, Christopher. El manifiesto Cluetrain. Barcelona: Deusto, 2009. ISBN 9788423426935

2. Definidas en Aerco; Territorio creativo. La función del community manager: cómo las empresas están organizándose para crear y hacer crecer sus comunidades.

http://www.aercomunidad.org/2009/11/11/la-funcion-del-communitymanager-descargate-el-white-paper/
3. http://www.web-strategist.com/blog/

4. En: Vicente, Alberto; Gozzer, Silvano. El community manager (I). Manual de comunicación online editorial.

http://www.anatomiadelaedicion.com/wordpress/wp-content uploads/2010/01/manual-de-comunicacion-online-editorial-1.pdf

5. Se han consultado Infojobs y Tecnoempleo en el período febrero-marzo de 2010. Se han tenido en cuenta ofertas con los siguientes puestos demandados: community manager, online marketing manager, digital manager, técnico de comunicación y gestor de comunidades.

http://www.infojobs.net/

http://www.tecnoempleo.com/

6. Agencia Nacional de la Evaluación de la Calidad y Acreditación (Aneca) http://www.aneca.es/media/150424/libroblanco_jun05_documentacion.pdf

7. Rethinking

http://lisjobs.com/rethinking/

Javier Leiva-Aguilera, Catorze Asesoría Internet $S L$ http://www.catorze.com

javier@catorze.com

\section{ProQuest

\section{ProQuest Entrepreneurship}

\section{ACCESO SIN PRECEDENTES A UNA AMPLIA SELECCIÓN DE HERRAMIENTAS PARA EL ESTUDIO Y LA PRÁCTICA DE LA INICIATIVA EMPRESARIAL.}

- Videoclips con consejos de emprendedores de éxito (eClipsNet de Cornell University).

- Completas herramientas para emprendedores: plantillas, ejemplos de planes de negocio, casos prácticos (Business Cases de Ivey, Darden, Babson) y mucho más.

- Recopilación de investigación de miles de recursos académicos, incluyendo títulos de Emerald, Palgrave y SSRN working papers.

- Datos prácticos e investigación de mercado para la evaluación de nuevos productos e ideas, tal como Snapshots Industry Reports y Hoovers Company Profiles.

ProQuest Entrepreneurship tiene la misma interfaz de usuario y se puede utilizar al mismo tiempo que otras bases de datos como ABI/INFORM, para proporcionar a los usuarios los resultados más completos.

\section{$\mathrm{ABI} /$ INFORM $^{\circledR}$}

\section{LA BASE DE DATOS DE REVISTAS DE ECONOMÍA Y GESTIÓN LÍDER DEL MERCADO, AL ALCANCE DE SUS MANOS.}

- Extensa cobertura de todas las disciplinas en el área de los negocios.

- Más de 4.000 títulos, incluido el acceso en exclusiva a MIT Sloan Management Review, Rand Journal of Economics, European Management Review, The Wall Street Journal.

- Contenido de publicaciones no periódicas como EIU ViewsWire Country Reports, y más de 30.000 tesis de economía y negocios en texto completo.

- Líder del mercado en indización de economía y negocios durante más de 30 años. 

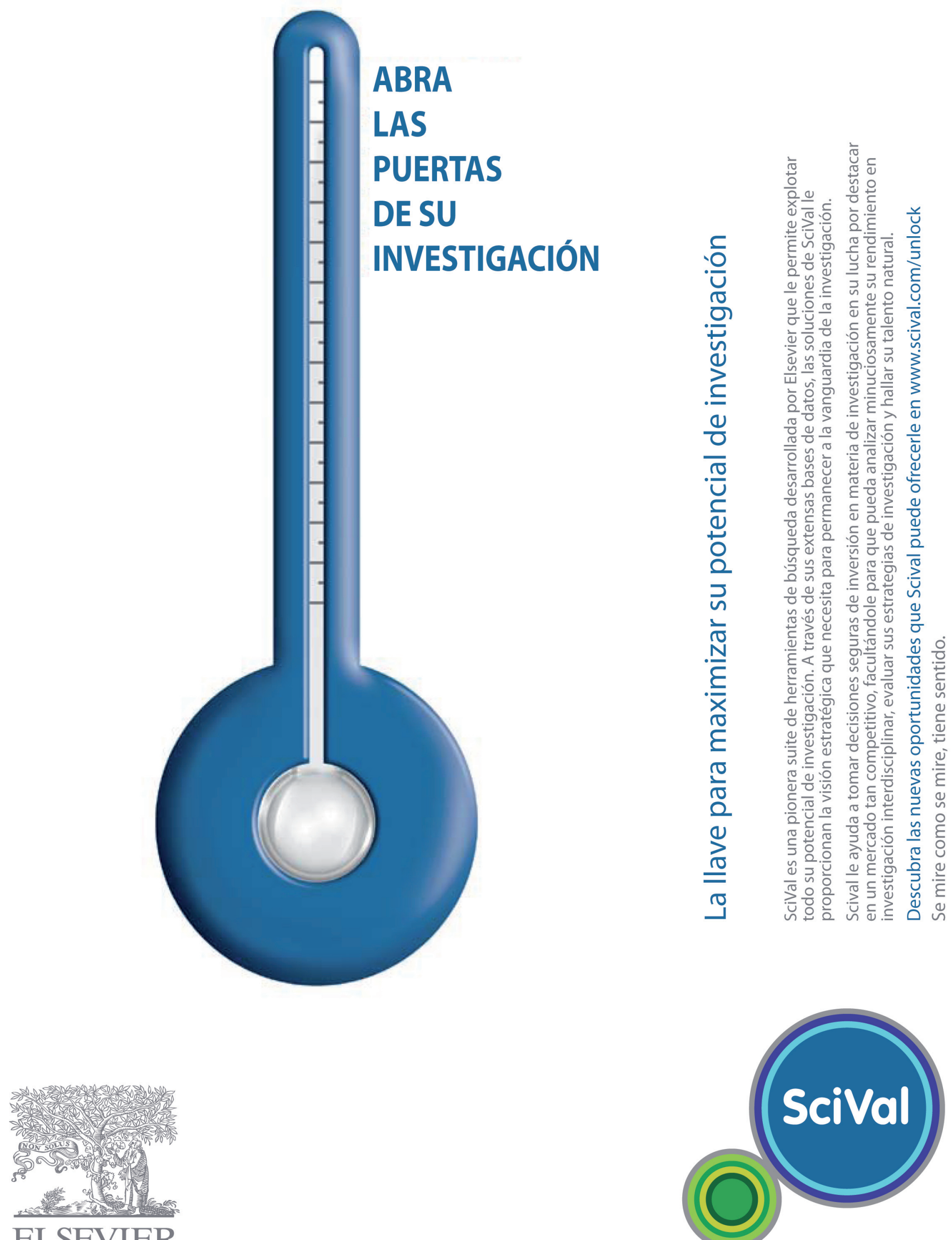

Scival 